\title{
Two-component Signal Transduction in Synechocystis sp. PCC 6803 under Phosphate Limitation: Role of Acetyl Phosphate
}

\author{
Waraporn Juntarajumnong ${ }^{1}$, Julian J. Eaton-Rye ${ }^{2}$ and Aran Incharoensakdi, ${ }^{1, *}$ \\ ${ }^{1}$ Department of Biochemistry, Faculty of Science, Chulalongkorn University, Bangkok 10330, Thailand \\ ${ }^{2}$ Department of Biochemistry, University of Otago, P.O. Box 56, Dunedin, New Zealand
}

Received 24 January 2007, Accepted 23 April 2007

The two-component signal transduction, which typically consists of a histidine kinase and a response regulator, is used by bacterial cells to sense changes in their environment. Previously, the SphS-SphR histidine kinase and response regulator pair of phosphate sensing signal transduction has been identified in Synechocystis sp. PCC 6803. In addition, some response regulators in bacteria have been shown to be cross regulated by low molecular weight phosphorylated compounds in the absence of the cognate histidine kinase. The ability of an endogenous acetyl phosphate to phosphorylate the response regulator, SphR in the absence of the cognate histidine kinase, $\mathrm{SphS}$ was therefore tested in Synechocystis sp. PCC 6803. The mutant lacking functional SphS and acetate kinase showed no detectable alkaline phosphatase activity under phosphate-limiting growth conditions. The results suggested that the endogenous acetyl phosphate accumulated inside the mutants could not activate the SphR via phosphorylation. On the other hand, exogenous acetyl phosphate could allow the mutant lacking functional acetate kinase and phosphotransacetylase to grow under phosphate-limiting conditions suggesting the role of acetyl phosphate as an energy source. Reverse transcription PCR demonstrated that the transcripts of acetate kinase and phosphotransacetylase genes in Synechocystis sp. PCC 6803 is upregulated in response to phosphate limitation suggesting the importance of these two enzymes for energy metabolism in Synechocystis cells

Keywords: Acetate kinase, Acetyl phosphate, Phosphotransacetylase, SphR, SphS and Synechocystis sp. PCC 6803

* To whom correspondence should be addressed.

Tel: 66-2-218-5419; Fax: 66-2-218-5418

E-mail: aran.i@chula.ac.th
Introduction

Bacteria frequently use two-component signal transduction pathways for environmental sensing (Hsing et al., 1998). These systems consist of a sensor histidine kinase and a response regulator. When a change in the environment is detected, a specific histidine residue in the histidine kinase is autophosphorylated and subsequently the phosphoryl group is transferred to an aspartate residue on the cognate response regulator. The phosphorylated response regulator undergoes a conformational change that directs an output response. Typically the response regulator is a transcriptional regulator which upon phosphorylation alters gene expression in response to the stimulus (Parkinson and Kofoid, 1992). In addition to phosphoryl group transfer between a sensor kinase and a response regulator, some response regulators have been shown to be phosphorylated by low molecular weight compounds such as phosphoamidate, carbamyl phosphate and acetyl phosphate (Stock et al., 1995).

The pathway for acetyl phosphate synthesis is controlled by the enzymes acetate kinase (E.C.2.7.2.1) and phosphotransacetylase (E.C.2.3.1.8), which are encoded by the ack and pta genes, respectively (Summers et al., 1999). This pathway is also involved in an incorporation of $\mathrm{P}_{\mathrm{i}}$ into ATP which is the primary phosphoryl donor in metabolism (Wanner and Wilmes-riesenberg, 1992). Apart from acetyl phosphate, acetyl-CoA is a central metabolite for many anabolic processes. The fluctuation of acetyl-CoA levels in response to changing growth conditions may therefore determine acetyl phosphate levels as a result of the changes in the expression of the ack and pta genes (Summers et al., 1999). The regulation of the acetate kinase and phosphotransacetylase genes has been studied in Methanosarcina thermophilla under different growth conditions (SinghWissmann and Ferry, 1995) and Sinorhizobium meliloti under phosphate stress (Summers et al., 1999).

Phosphate is an essential nutrient required for the biosynthesis of biomolecules. However, phosphate is one of the most 
limiting nutrients in the environment (Suzuki et al., 2004). The phosphate sensing two-component system has been extensively studied in Escherichia coli. It involved a phosphorelay between the histidine kinase PhoR and the response regulator $\mathrm{PhoB}$ which controls the expression of the gene in the Pho regulon as monitored by measuring alkaline phosphatase activity (Hirani et al., 2000). In the absence of PhoR function, the PhoM which is the histidine kinase probably detected as an intermediate in the central metabolism (Wanner and Wilmes-riesenberg, 1992; Hiratsu et al., 1995) can crosstalk to activate $\mathrm{PhoB}$ for Pho regulon regulation (Lee et al., 1990). However, PhoR appears to play dominant role in the regulation of the Pho regulon (Amemura et al., 1990). Furthermore, PhoB was found to be phosphorylated by acetyl phosphate in vitro (Hiratsu et al., 1995). Previously, the SphSSphR two-component signal transduction system has been identified in Synechocystis sp. PCC 6803. These proteins are homologous to PhoR and PhoB, respectively (Hirani et al., 2000; Suzuki et al., 2004). They are involved in the perception and transduction of phosphate deprivation signals which regulates the induction of two sets of genes encoding phosphate specific transport systems (Pst1 and Pst2), extracellular nuclease (NucH) and alkaline phosphatase (PhoA). An additional single gene, urtA, encoding an unknown function of periplasmic protein was highly repressed under phosphate starvation (Suzuki et al., 2004). Synechocystis sp. PCC 6803 is a suitable model for studies of stress responses. It is naturally competent, i.e. the foreign DNA can be taken up and integrated into the genome by homologous recombination at high frequency. Moreover, the complete nucleotide sequence of the genome is available (Hirani et al., 2000; Hirani, 2001; Murata and Suzuki, 2006).

In the present study, the mutants lacking SphS, acetate kinase, and phosphotransacetylase were constructed and used as double or triple mutant to investigate the possible role of endogenous acetyl phosphate as a phosphorylating agent for $\mathrm{SphR}$ as well as to test whether exogenous acetyl phosphate could serve as an energy source for Synechocystis cells grown under phosphate-limiting conditions. Furthermore, the expression of acetate kinase and phosphotransacetylase genes under phosphate-limiting conditions was also investigated.

\section{Material and Methods}

Growth conditions. The growth of wild type and mutants of Synechocystis sp. PCC 6803 in BG-11 and phosphate-limiting BG11 , in which phosphate was replaced by an equimolar solution of $\mathrm{KCl}$, was carried out as described previously (Hirani et al., 2000). Where required, chloramphenicol was added at a concentration of $15 \mu \mathrm{g} / \mathrm{ml}$, spectinomycin or kanamycin was added at a concentration of $25 \mu \mathrm{g} / \mathrm{ml}$. The E. coli DH5 $\alpha$ was grown in LB medium supplemented with ampicillin $(50 \mu \mathrm{g} / \mathrm{ml})$, and spectinomycin or kanamycin $(50 \mu \mathrm{g} / \mathrm{ml})$, or chloramphenicol $(30 \mu \mathrm{g} / \mathrm{ml})$ as required. In some experiments acetyl phosphate was added to phosphatelimiting BG-11 at $20 \mu \mathrm{M}$. For photoautotrophic growth curve measurements the method described by Morgan et al. (1998) was followed except that cultures were grown in the absence of glucose.

Construction of knockout plasmids. The histidine kinase, SphS gene (sll0337) was amplified by PCR with the forward primer 5'GGACAGTGACGAGCGG-3' and the reverse primer 5'-CCCAGC CTCTCAACCA-3' that were 1,069 nucleotides upstream of the GTG start codon and 657 nucleotides downstream of the TAG stop codon, respectively. The sll0337 gene was cloned into pUC18. The spectinomycin-resistance cassette was inserted in psll0337 at a unique Xba I site.

The acetate kinase gene (sll1299) was amplified by PCR with the forward primer 5'-CGTGGCGATCGCCCCGGCCATTTATCAAC GG-3' and the reverse primer 5'-CGTGTTGGCGGATGCGGATCT AGCCAAGG-3' that were 530 nucleotides upstream of the ATG start codon and 85 nucleotides downstream of the TAA stop codon, respectively. The sll1299 gene was cloned into pUC19. A kanamycinresistance cassette was inserted in psll1299 between two Hpa I sites.

The phosphotransacetylase gene (slr2132) was amplified by PCR with the forward primer 5'-GCTATCACTTAAGTAGGTGG3' and the reverse primer 5'-CCATAGGCATAGCTGACCACT-3' that were 115 nucleotides upstream of the ATG start codon and 138 nucleotides downstream of the TAA stop codon, respectively. The slr2132 gene was cloned into pGEMT-Easy (Promega). A chloramphenicol-resistance cassette was inserted in pslr2132 at the BstE II site.

The resulting plasmids were transformed into Synechocystis sp. PCC 6803 as described by Williams (1988).

RNA extraction. The RNA was extracted from exponentially growing cultures of wild-type Synechocystis sp. PCC 6803 in normal BG-11 or phosphate-limiting BG-11. The cell pellet was collected and frozen in liquid nitrogen and stored at $-80^{\circ} \mathrm{C}$. The frozen pellet was resuspended in phenol at $65^{\circ} \mathrm{C}$ followed by the addition of $50 \mathrm{mM}$ sodium acetate $(\mathrm{pH} 5.1), 10 \mathrm{mM}$ EDTA, $1 \%$ SDS. The cells were placed on ice and then disrupted by glass beads using a mini bead-beater (BioSpec Products, Inc.). The samples were centrifuged and the top phase was subjected to two phenol:chloroform extractions followed by one chloroform extraction. The RNA was precipitated by ethanol and the pellet resuspended in diethyl pyrocarbonate-treated water followed by the addition of $10 \mathrm{M} \mathrm{LiCl}$. The solution was centrifuged and the pellet rinsed in $2 \mathrm{M} \mathrm{LiCl}$ and dissolved in diethyl pyrocarbonate-treated water. The RNA was then precipitated with two volumes of ethanol and $1 / 10$ volume of $3.5 \mathrm{M}$ sodium acetate $(\mathrm{pH} 6.0)$. Finally, the RNA pellet was dried and resuspended in diethyl pyrocarbonatetreated water and stored at $-80^{\circ} \mathrm{C}$.

Reverse transcription-polymerase chain reaction (RT-PCR) analysis. The RNA sample was treated with DNase I prior to RTPCR. One unit of DNase I and $1 \mu \mathrm{l}$ of $10 \times$ DNase I reaction buffer were added to $1 \mu \mathrm{g}$ of RNA. The RT step for production of cDNA was carried out by using Superscript II. The DNase-treated RNA was added to Superscript II buffer containing 10 pmol of the reverse primer. For sll1299 this was 5'-CTTGAGGAATGGGATAT TCG-3' and for slr2132, 5'-CTTTGCACTGCCTTGTAAGT-3'. The reverse primer for the $p s b B$ gene 5'-CTTCTTCCGGGTGGAAAG 
G-3' was also used to assess the constitutive expression of this gene as a control. The enzyme was omitted from reaction mixtures that were used as negative controls in the RT-PCR analysis.

For the PCR step the forward primers of sll1299 5'-GTCTTTAT GAGCTGACTGGCGAT-3', slr2132 5'-CCTAAAACTAGCCCAG ACCGAGA-3' and $p s b B$ 5'-ACCGGTGCTATGAACAGTGG-3' were used and were situated upstream of the original reverse primers used for the RT reactions.

Alkaline phosphatase assay. Cells were grown in BG-11 or phosphate-limiting BG-11 for $24 \mathrm{~h}$. The enzyme assays were carried out according to Hirani et al. (2000) and activity expressed as arbitrary units.

Verification of mutant strains. The $s p h \mathrm{~S}$, ack and pta gene from mutants was amplified by colony PCR as described by Eaton-Rye (2004) to establish that the strains had been fully segregated.

\section{Results}

It has been known that PhoB can be activated by acetyl phosphate via Pta-Ack pathway in E. coli (Wanner and Wilmesriesenberg, 1992; Wanner, 1995). In order to determine whether this activation could occur in Synechocystis cells in the absence of $\mathrm{SphS}$, the $\Delta \mathrm{Ack} / \Delta \mathrm{SphS}$ strain was constructed so that the accumulated endogenous acetyl phosphate in this mutant may provide the chance for phosphorylation of SphR by acetyl phosphate. In addition, $\Delta \mathrm{Pta} / \Delta \mathrm{SphS}$ and $\Delta \mathrm{Pta} / \Delta \mathrm{Ack} / \Delta \mathrm{SphS}$ mutants were also constructed which contained lower acetyl phosphate levels. The homozygosity of all these strains was then verified by PCR (Fig. 1). There was only a single band of $4.2 \mathrm{~kb}$ in the $\Delta \mathrm{Ack} / \Delta \mathrm{SphS}, \Delta \mathrm{Pta} / \Delta \mathrm{SphS}$ and $\Delta \mathrm{Pta} / \Delta \mathrm{Ack} / \Delta \mathrm{SphS}$ while the wild type produced $2.2 \mathrm{~kb}$ PCR product using $s p h S$ primers (Fig. 1A). The PCR products using ack primers showed a single band of $1.9 \mathrm{~kb}$ for wild type whereas the band of $2.5 \mathrm{~kb}$ was observed for $\Delta \mathrm{Ack} / \Delta \mathrm{SphS}$ and $\Delta \mathrm{Pta} / \Delta \mathrm{Ack} / \Delta \mathrm{SphS}$ strains (Fig. 1B). The obtained PCR products conformed to the predicted sizes. It can be seen that the $\Delta \mathrm{Pta} / \Delta \mathrm{SphS}$ and $\Delta \mathrm{Pta} / \Delta \mathrm{Ack} / \Delta \mathrm{SphS}$ strains possessed the expected single band at $4.5 \mathrm{~kb}$ while single band of $2.4 \mathrm{~kb}$ was obtained from wild type using pta primers (Fig. 1C). There was a difference in size of a single PCR product between wild type and mutant strains. Furthermore, all mutant strains showed no PCR product with the same size as that of the wild type. Altogether, these results confirmed that the introduced copy of interrupted genes had been fully segregated.

\section{Acetyl phosphate cannot activate $S p h R$ in the absence of} SphS. The alkaline phosphatase activities of mutants and wild type grown under phosphate-sufficient and phosphate-limiting conditions were monitored. Fig. 2 shows that the induction of alkaline phosphatase activity was observed in wild type grown under phosphate-limiting BG-11 (Fig. 2, lane 1). However, there was no induction of alkaline phosphatase of the $\Delta \mathrm{Ack} /$ $\Delta \mathrm{SphS}, \Delta \mathrm{Pta} / \Delta \mathrm{SphS}$ and $\Delta \mathrm{Pta} / \Delta \mathrm{Ack} / \Delta \mathrm{SphS}$ mutants even under phosphate-limiting BG-11 (Fig. 2, lanes 2, 3, 4). The results suggest that the endogenous acetyl phosphate cannot cross regulate $\mathrm{SphR}$ in the absence of $\mathrm{SphS}$.

Acetyl phosphate can provide energy source for growth. From a previous study, the addition of acetyl phosphate could restore endogenous levels of ATP in the Synechocystis cells under phosphate-limiting BG-11 (Hirani et al., 2000). The $\Delta \mathrm{Pta} / \Delta \mathrm{Ack} / \Delta \mathrm{SphS}$ mutant was constructed to test whether the energy for the cells could be provided by exogenous acetyl phosphate. The wild-type and the $\Delta \mathrm{Pta} / \Delta \mathrm{Ack} / \Delta \mathrm{SphS}$ strains were grown photoautotrophically under normal and phosphatelimiting BG-11 for 6 days (Fig. 3A). The cells were collected and growth was continued under normal, phosphate-limiting BG-11 and phosphate-limiting BG-11 containing $20 \mu \mathrm{M}$ acetyl phosphate for another 6 days (Fig. 3B).

The first 6 days growth of wild type and the $\Delta \mathrm{Pta} / \Delta \mathrm{Ack} /$ $\Delta \mathrm{SphS}$ mutant was slightly retarded under phosphate-limiting BG-11 (Fig. 3A). The specific growth rates of wild type and the mutant under normal BG-11 were 0.059 and $0.051 \mathrm{~h}^{-1}$, respectively, whereas the specific growth rates under phosphate limitation were 0.053 and $0.038 \mathrm{~h}^{-1}$, respectively. Cells at day 6 were collected and used to start a new photoautotrophic growth curve for another 6 days. The wild type and the mutant could not grow under phosphate limitation presumably due to the depletion of phosphate reserves (Fig. 3B, two lower curves). However, after the first 24 hours adaptation, both the wild type and the mutant under phosphate limitation containing $20 \mu \mathrm{M}$ acetyl phosphate, showed similar specific growth rate $\left(0.043 \mathrm{~h}^{-1}\right)$ (Fig. $3 \mathrm{~B}$, two middle curves) to those under normal BG-11 (0.047 $\left.\mathrm{h}^{-1}\right)$ (Fig. 3B, two upper curves). These results indicated that exogenous acetyl phosphate can provide phosphate for the cell even though acetate kinase and phosphotransacetylase were absent in the $\Delta \mathrm{Pta} / \Delta \mathrm{Ack} / \Delta \mathrm{SphS}$ mutant.

Up-regulation of acetate kinase and phosphotransacetylase by phosphate deprivation. The acetate kinase and phosphotransacetylase of Synechocystis sp. PCC 6803 are encoded by sll1299 and slr2132, respectively. To monitor the mRNA levels of acetate kinase and phosphotransacetylase, RT-PCR was performed. The total RNA was extracted from wild-type Synechocystis sp. PCC 6803 cells grown under normal BG-11 and phosphate-limiting BG-11. The RT-PCR was carried out using specific primers to produce cDNA of these genes. The cDNA of $p s b B$ was also produced to serve as a control showing constitutive mRNA levels in both conditions. The amount of the PCR product of $p s b B(0.52 \mathrm{~kb})$ under normal conditions was similar to that under phosphate-limiting conditions (Fig. 4A and 4B, lanes 2 and 4). These bands were used as the internal control to confirm that the different levels of PCR product obtained from the acetate kinase and phosphotransacetylase cDNA resulted from the different mRNA levels obtained from differential gene expression. The expected sizes of the PCR products, $0.48 \mathrm{~kb}$ bands for the acetate kinase gene (Fig. 4A, lanes 2 and 4 ) and $0.63 \mathrm{~kb}$ bands 
(A)

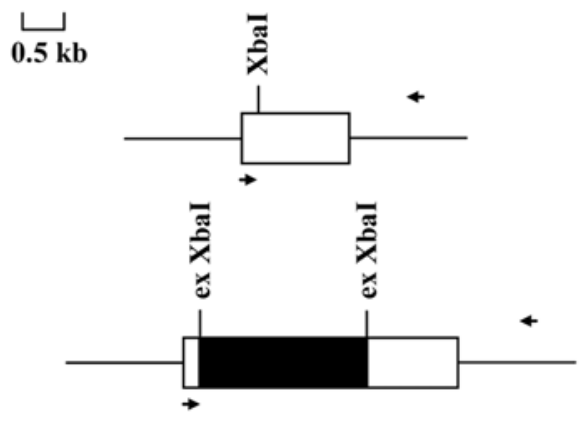

(B)

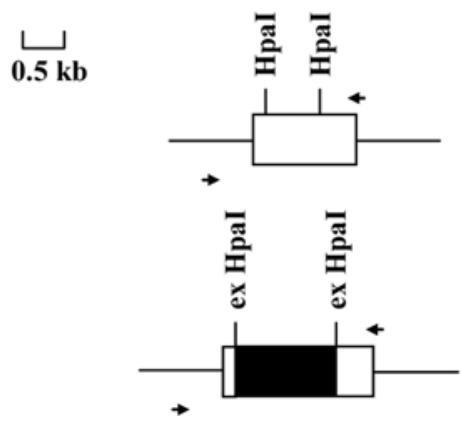

(C)

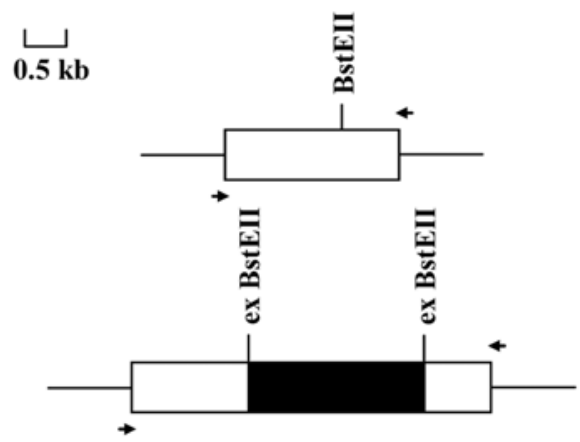

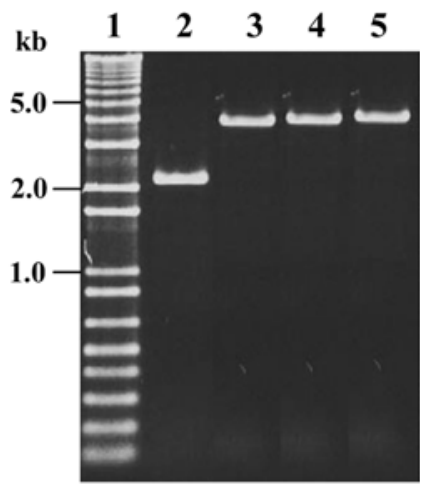
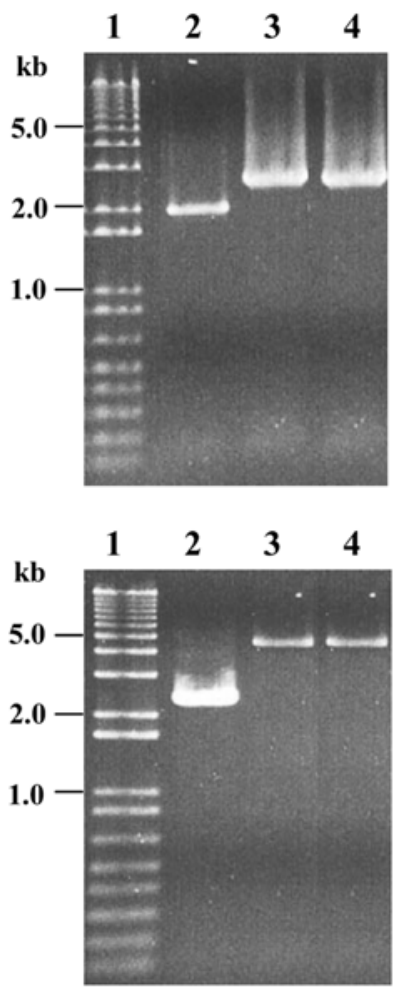

Fig. 1. Construction of $\Delta$ SphS, $\Delta$ Ack and $\Delta$ Pta strains. (A) Diagram of $s p h S$ showing the gene interrupted by a $2.0 \mathrm{~kb}$ spectinomycinresistance cassette inserted at a unique $X b a$ I site (left panel). The sphS gene and spectinomycin-resistance cassette are shown as open and black boxes, respectively. The location of the primers used for the PCR are indicated by arrows. Colony PCR demonstrating full segregation of the gene encoding the antibiotic-resistance cassette is shown on the right panel. $1 \mathrm{~Kb}$ Plus DNA marker (Invitrogen, Carlsbad, CA) (lane 1), wild type (lane 2), $\Delta \mathrm{Ack} / \Delta \mathrm{SphS}$ (lane 3), $\Delta \mathrm{Pta} / \Delta \mathrm{SphS}$ (lane 4) and $\Delta \mathrm{Ack} / \Delta \mathrm{Pta} / \Delta \mathrm{SphS}$ (lane 5). (B) Diagram of ack showing the gene interrupted by a $1.2 \mathrm{~kb}$ kanamycin-resistance cassette inserted between two HpaI sites (left panel). The ack gene and kanamycin-resistance cassette are shown as open and black boxes, respectively. The location of the primers used for the PCR are indicated by arrows. Colony PCR demonstrating full segregation of the gene encoding the antibiotic-resistance cassette is shown on the right panel. $1 \mathrm{~Kb}$ Plus DNA marker (Invitrogen, Carlsbad, CA) (lane 1), wild type (lane 2), $\Delta \mathrm{Ack} / \Delta \mathrm{SphS}$ (lane 3 ) and $\Delta \mathrm{Ack} / \Delta \mathrm{Pta} /$ $\Delta$ SphS (lane 4). (C) Diagram of pta showing the gene interrupted by a $2.2 \mathrm{~kb}$ chloramphenicol-resistance cassette inserted at a unique BstEII site (left panel). The pta gene and chloramphenicol-resistance cassette are shown as open and black boxes, respectively. The location of the primers used for the PCR are indicated by arrows. Colony PCR demonstrating full segregation of the gene encoding the antibiotic-resistance cassette is shown on the right panel. $1 \mathrm{~Kb}$ Plus DNA marker (Invitrogen, Carlsbad, CA) (lane 1), wild type (lane 2), $\Delta \mathrm{Pta} / \Delta \mathrm{SphS}$ (lane 3) and and $\Delta \mathrm{Pta} / \Delta \mathrm{Ack} / \Delta \mathrm{SphS}$ (lane 4).

of the phosphotransacetylase gene (Fig. 4B, lanes 2 and 4), were obtained. The results of the negative control experiment (Fig. 4A and 4B, lanes 3 and 5) showed that there was no genomic DNA in the RNA sample in the RT-PCR reaction.
The levels of the PCR products of both ack and pta genes were higher in phosphate-limiting BG-11 than in normal BG11. The results indicated that the regulation of phosphotransacetylase and acetate kinase synthesis occurred, at least 


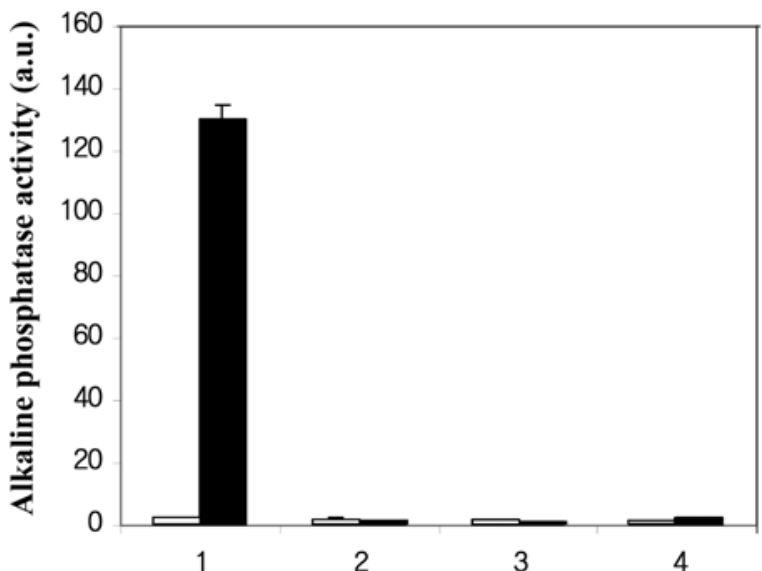

Fig. 2. Measurement of alkaline phosphatase activity in $\Delta \mathrm{Ack} /$ $\Delta$ SphS under phosphate-sufficient and phosphate-limiting BG-11. Cells were grown under normal BG-11 (open bars) and phosphatelimiting BG-11 (closed bars). The strains were wild type (1), $\Delta \mathrm{Ack} / \Delta \mathrm{SphS}(2), \Delta \mathrm{Pta} / \Delta \mathrm{SphS}$ (3) and $\Delta \mathrm{Ack} / \Delta \mathrm{Pta} / \Delta \mathrm{SphS}$ (4). The data represent Mean $\pm \mathrm{SD}, \mathrm{n}=3$.

in part, at the mRNA level under phosphate insufficient conditions.

\section{Discussion}

Bacterial response regulators can be phosphorylated, in vitro, by low molecular weight phosphoryl donor such as phosphoramidate, acetyl phosphate and carbamyl phosphate (McCleary et al., 1993; Kakuda et al., 1994). There are some reports on the involvement of acetyl phosphate in the Pho regulon regulation in vivo (Wanner and Wilmes-riesenberg,
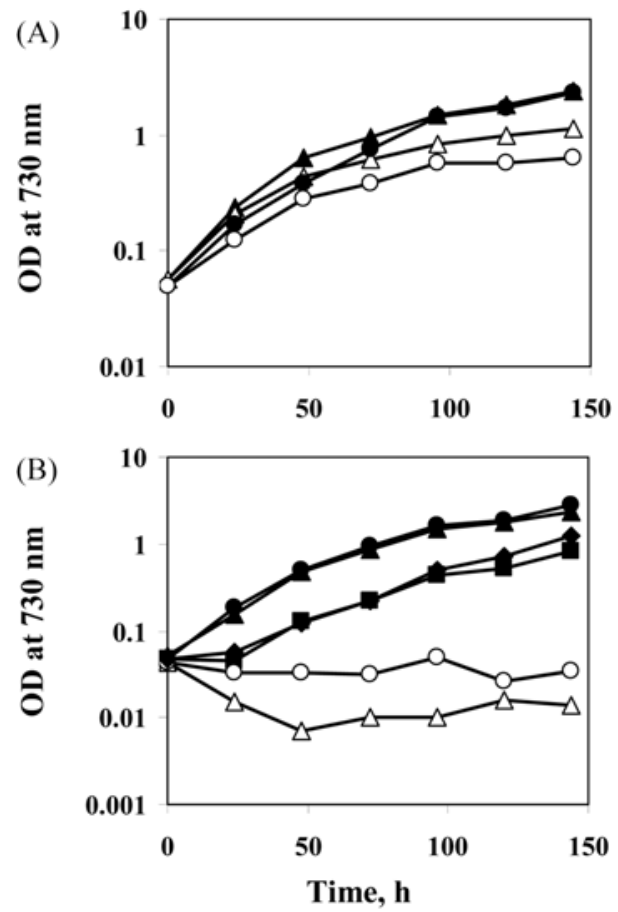

Fig. 3. Photoautotrophic growth of wild type and $\Delta \mathrm{Pta} / \Delta \mathrm{Ack} /$ $\Delta$ SphS mutant. (A) First phase, and (B) second phase of photoautotrophic growth of strains as measured by the optical density at $730 \mathrm{~nm}$ under different conditions. $\mathbf{\Delta}$, are wild type and mutant respectively under BG-11. $\triangle, \bigcirc$ are wild type and mutant respectively under phosphate-limiting BG-11. are wild type and mutant respectively under phosphate-limiting BG-11 supplemented with $20 \mu \mathrm{M}$ acetyl phosphate.

1992). Moreover, acetyl phosphate is a signal for transcriptional activation of the Pho regulon in PhoR PhoM mutants by

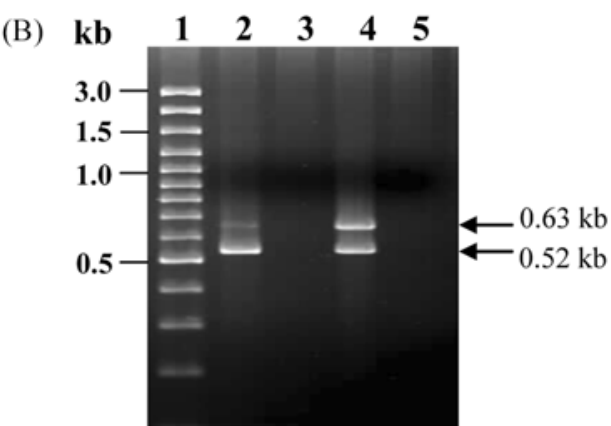

Fig. 4. RT-PCR analysis of ack and pta expression in Synechocystis sp. PCC 6803. (A) RT-PCR products of the gene encoding acetate kinase from wild-type cells grown under normal and phosphate-limiting BG-11. $1 \mathrm{~Kb}$ Plus DNA marker (Invitrogen, Carlsbad, CA) (lane 1), $a c k$ and $p s b B$ levels obtained with normal BG-11 (lane 2), negative control in which no reverse transcriptase was added to the RNA sample obtained under normal BG-11 (lane 3), $a c k$ and $p s b B$ levels obtained with phosphate-limiting BG-11 (lane 4) and negative control in which no reverse transcriptase was added to the RNA sample obtained under phosphate-limiting conditions (lane 5). (B) RTPCR products of the gene encoding phosphotransacetylase from cells grown under normal and phosphate-limiting BG-11. $1 \mathrm{~Kb}$ Plus DNA marker (Invitrogen) (lane 1), pta and $p s b B$ levels obtained with normal BG-11 (lane 2), negative control in which no reverse transcriptase was added to the RNA sample obtained in normal BG-11 (lane 3), pta and $p s b B$ levels obtained with phosphate-limiting BG-11 (lane 4) and negative control in which no reverse transcriptase was added to the RNA sample obtained under phosphate-limiting conditions (lane 5). 
serving as a substrate for autophosphorylation of PhoB (Amemura et al., 1990; Lee et al., 1990; Hiratsu et al., 1995). Thus, the concentration of phosphoryl donors in the cells is significant for signal transduction activation (Kakuda et al., 1994).

The Pta-AckA pathway also appears to be involved in acetyl phosphate synthesis (Wanner and Wilmes-riesenberg, 1992). The acetyl phosphate is made from acetyl-CoA via Pta and broken down by AckA in the Escherichia coli cells grown on glucose or pyruvate. However, previous studies showed no evidence on the cross regulation of SphR by acetyl phosphate when the Synechocystis cells were grown photoheterotrophically in the presence of $10 \mu \mathrm{M}$ diuron (Hirani et al., 2000). In this study a role of acetyl phosphate, a non-cognate sensor kinase, in response regulator activation was tested. The pta and ack knockout mutants were constructed in combination with the sphS knockout in Synechocystis sp. PCC 6803. The Ack mutation would bring about elevated acetyl phosphate levels because of a block in its breakdown and the Pta mutation resulted in lower acetyl phosphate levels because of a block in its synthesis (Morrison et al., 2005; Wanner and Wilmesriesenberg, 1992; Wolfe, 2005).

The results in Fig. 2 provided evidence that, as far as alkaline phosphatase activity was concerned, acetyl phosphate could not activate $\mathrm{SphR}$ in the absence of cognate histidine kinase SphS. The $\Delta \mathrm{Pta} / \Delta \mathrm{SphS}$ and $\Delta \mathrm{Pta} / \Delta \mathrm{Ack} / \Delta \mathrm{SphS}$ mutants contained low levels of acetyl phosphate whereas the $\Delta \mathrm{Ack} /$ $\Delta$ SphS mutant contained elevated levels of acetyl phosphate. We would expect that the $\Delta \mathrm{Ack} / \Delta \mathrm{SphS}$ mutant showed an induction of alkaline phosphatase under phosphate-limiting conditions if the high level of acetyl phosphate accumulated in this mutant could phosphorylate SphR. On the contrary, alkaline phosphatase activity of $\Delta \mathrm{Ack} / \Delta \mathrm{SphS}$ mutant was not induced under phosphate-limiting conditions (Fig. 2, lane 2). The results implied that SphR may not be cross regulated by endogenous acetyl phosphate in Synechocystis sp. PCC 6803. Thus, it is likely that the SphR cannot be phosphorylated by phosphoryl group from acetyl phosphate, in vivo. In contrast, the PhoB in Escherichia coli has been shown to be directly phosphorylated by acetyl phosphate in vitro (McCleary and Stock, 1994). However, we cannot rule out the possibility that acetyl phosphate may need other additional factors for its indirect role in the cross regulation in Synechocystis cells.

The ack and pta genes in Synechocystis cells were upregulated under phosphate-limitation (Figs. 4A and 4B). Constitutively low levels of these two genes were detected under normal conditions. The up-regulation of ack and pta genes indicated that the existing levels of acetyl phosphate might be high during the conversion of acetyl-CoA via acetyl phosphate to acetate by the Pta-AckA pathway. However, since acetyl phosphate did not play a role in the phosphorylation of SphR, it is thus likely that acetyl phosphate acts as a highenergy compound in Synechocystis cells. This was corroborated by the results showing that exogenous acetyl phosphate could allow Synechocystis cells to grow even when the Pta-AckA pathway was non-functional (Fig. 3B). Whether acetyl phosphate in Synechocystis cells can directly generate ATP via the action of acetate kinase remains to be further investigated.

Acknowledgment This work was supported by Thailand Research Fund through the Royal Golden Jubilee Ph.D. Program to A. Incharoensakdi and W. Juntarajumnong.

\section{References}

Amemura, M., Makino, K., Shinagawa, H. and Nakata, A. (1990) Cross talk to the phosphate regulon of Escherichia coli by PhoM protein: PhoM is a histidine protein kinase and catalyzes phosphorylation of $\mathrm{PhoB}$ and $\mathrm{PhoM}$-open reading frame 2. J. Bacteriol. 172, 6300-6307.

Eaton-Rye, J. J. (2004) The construction of gene knockouts in the cyanobacterium Synechocystis sp. PCC 6803; in Photosysthesis Research Protocols, Carpentier, R. (ed.), pp. 309-324, Humana Press, Totowa, USA.

Hirani, T. A. (2001) Identification and characterization of a twocomponent system involved in phosphate sensing in Synechocystis sp. PCC 6803. Ph. D. thesis. University of Otago, New Zealand.

Hirani, T. A., Suzuki, I., Murata, N., Hayashi, H. and Eaton-Rye, J. J. (2000) Characterization of a two-component signal transduction system involved in the induction of alkaline phosphatase under phosphate-limiting conditions in Synechocystis sp. PCC 6803. Plant Mol. Biol. 45, 133-144.

Hiratsu, K., Nakata, A., Shinagawa, H. and Makino, K. (1995) Autophosphorylation and activation of transcriptional activator PhoB of Escherichia coli by acetyl phosphate in vitro. Gene 161, 7-10.

Hsing, W., Russo, F. D., Bernd, K. K. and Silhavy, T. J. (1998) Mutations that alter the kinase and phosphatase activities of the two-component sensor EnvZ. J. Bacteriol. 180, 4583-4586.

Kakuda, H., Hosono, K., Shiroishi, K. and Ichihara, S. (1994) Identification and characterization of the ackA (acetate kinase A)-pta (phosphotransacetylase) operon and complementation analysis of acetate utilization by an ackA-pta deletion mutant of Escherichia coli. J. Biochem. 116, 916-922.

Lee, T., Makino, K., Shinagawa, H. and Nakata, A. (1990) Overproduction of acetate kinase activates the phosphate regulon in the absence of the phoR and phoM functions in Escherichia coli. J. Bacteriol. 172, 2245-2249.

McCleary, W. R. and Stock, J. B. (1994) Acetyl phosphate and the activation of two-component response regulators. J. Biol. Chem. 269, 31467-31572.

McCleary, W. R., Stock, J. B. and Ninfa, A. J. (1993) Is acetyl phosphate a global signal in Escherichia coli? J. Bacteriol. 175, 2793-2798.

Morgan, T. R., Shand, J. A., Clarke, S. M. and Eaton-Rye, J. J. (1998) Specific requirements for cytochrome $c$-550 and the manganese-stabilizing protein in photoautotrophic strains of Synechocystis sp. PCC 6803 with mutations in the domain Gly351 to Thr-436 of the chlorophyll-binding protein CP47. Biochemistry 37, 14437-14449.

Morrison, S. S., Mullineaux, C. W. and Ashby, M. K. (2005) The influence of acetyl phosphate on DspA signaling in the 
cyanobacterium Synechocystis sp. PCC6803. BMC Microbiol. 5, 47.

Murata, N. and Suzuki, I. (2006) Exploitation of genomic sequences in a systematic analysis to assess how cyanobacteria sense environmental stress. J. Exp. Bot. 57, 235-247.

Parkinson, J. S. and Kofoid, E. C. (1992) Communication modules in bacterial signaling proteins. Ann. Rev. Genet. 26, 71-112.

Singh-Wissmann, K. and Ferry, J. G. (1995) Transcriptional regulation of the phosphotransacetylase-encoding and acetate kinase-encoding genes ( $p t a$ and ack) from Methanosarcina thermophila. J. Bacteriol. 177, 1699-1702.

Stock, J. B., Surette, M. G., Levitt, M. and Park, P. (1995) Twocomponent signal transduction systems: structure-function relationships and mechanisms of catalysis. ; in Two-component Signal Transduction, Hoch, J. A. and Silhavy, T. J. (eds.), pp 25-51, American Society for Microbiology, Washington, USA.

Summers, M. L., Denton, M. C. and McDermott, T. R. (1999) Genes coding for phosphotransacetylase and acetate kinase in Sinorhizobium meliloti are in an operon that is inducible by phosphate stress and controlled by PhoB. J. Bacteriol. 181,
2217-2224.

Suzuki, S., Ferjan, A., Suzuk,i I. and Murata, N. (2004) The SphS-SphR two component system is the exclusive sensor for the induction of gene expression in response to phosphate limitation in Synechocystis. J. Biol. Chem. 279, 13234-13240.

Wanner, B. L. (1995) Signal transduction and cross regulation in the Escherichia coli phosphate regulon by PhoR, $\mathrm{CreC}$, and acetyl phosphate in Two-component Signal Transduction, Hoch, J. A. and Silhavy, T. J. (ed), pp. 203-221, American Society for Microbiology, Washington, USA.

Wanner, B. L. and Wilmes-riesenberg, M. R. (1992) Involvement of phosphotransacetylase, acetate kinase, and acetyl phosphate synthesis in control of the phosphate regulon in Escherichia coli. J. Bacteriol. 174, 2124-2130.

Williams, J. G. K. (1988) Construction of specific mutations in the photosystem II photosynthetic reaction center by genetic engineering methods in the cyanobacterium Synechocystis sp. PCC 6803. Methods Enzymol. 167, 776-778.

Wolfe, A. J. (2005) The acetate switch. Micro. Mol. Biol. Rev. 69, $12-50$. 